\title{
Prevalence of vertebral compression fractures due to osteoporosis in ankylosing spondylitis
}

\author{
Stuart H Ralston, Grant D K Urquhart, Maciej Brzeski, Roger D Sturrock
}

\begin{abstract}
Objective-To determine the prevalence of vertebral compression fractures due to osteoporosis in patients with ankylosing spondylitis.

Design-Prospective study of 111 consecutive patients; patients with vertebral compression fractures were entered into a case-control study.

Setting-Outpatient clinic at the centre for rheumatic diseases, Glasgow.

Patients-111 Consecutive patients with ankylosing spondylitis. Patients with compression fractures were matched for age and sex with two controls selected from the rest of the group. Patients with biconcave vertebral fractures were also studied.

Main outcome measures-Assessments of spinal deformity and mobility and analysis of lateral radiographs of spines for presence of syndesmophytes.

Results-Fifteen patients with compression fractures and five with biconcave fractures were studied. Compared with the controls the patients with compression fractures had increased formation of syndesmophytes in the lumbar spine, whereas those with biconcave fractures had increased formation throughout the spine. Patients with compression fractures also had a greater degree of spinal deformity (distance from wall to tragus $24.5 \mathrm{~cm} \mathrm{v}$ $12.7 \mathrm{~cm}$ in controls), less spinal mobility ( $20 v 45.6$ degrees of flexion), and reduced chest expansion $(2 \mathrm{~cm} \vee 3 \mathrm{~cm})$.
\end{abstract}

Conclusion-Vertebral compression fractures due to osteoporosis are a common but frequently unrecognised complication of ankylosing spondylitis and may contribute to the pathogenesis of spinal deformity and back pain.

Centre for Rheumatic Diseases, Glasgow Royal Infirmary, Glasgow G4 OSF Stuart H Ralston, MD, senior registrar

Maciej Brzeski, MRCP, registrar

Roger D Sturrock, MD, senior lecturer

Department of Radiology, North Ayrshire District General Hospital, Ayrshire Grant D K Urquhart, FRCR, locum consultant

Correspondence to: Dr Stuart H Ralston,

Rheumatic Diseases Unit, Northern General Hospital, Edinburgh EH5 2DQ.

BrMed f 1990;300:563-5

\section{Introduction}

Vertebral osteoporosis is a recognised feature of ankylosing spondylitis ${ }^{12}$ and is generally considered to be an asymptomatic radiological abnormality that is restricted to patients with advanced disease. ${ }^{13}$ Although the spines of patients with advanced disease are prone to fracture after trauma, ${ }^{4}$ spontaneous compression fractures as the result of osteoporosis are -considered to be rare. ${ }^{156}$

Recently, however, we observed multiple vertebral compression fractures due to severe spinal osteoporosis in a 32 year old man with moderately advanced ankylosing spondylitis. We performed a prospective study of patients with ankylosing spondylitis to determine the prevalence of this complication.

\section{Patients and methods}

The study group consisted of an unselected group of 111 patients with ankylosing spondylitis who consecutively attended an outpatient clinic for patients with seronegative spondyloarthropathy at the centre for rheumatic diseases over three months.
For each patient we recorded the clinical history, duration of disease, body weight, height, distance between the wall and tragus when the patient stood with his or her back against the wall, chest expansion, and total range of spinal flexion and extension as determined with a spondylometer. ${ }^{7}$ The mineral content of the distal third of the dominant radius was measured by single photon absorptiometry (Norland 287 bone densitometer).

We examined radiographs of each patient's pelvis and lumbar, thoracic, and cervical spine. Vertebral compression fractures were diagnosed if the ratio of the anterior vertebral height to the posterior vertebral height (measured to the nearest $\mathrm{mm}$ in lateral radiographs) was $<0.80$ for thoracic vertebrae or $<0.85$ for lumbar vertebrae. Vertebrae were excluded if the morphological appearances noted by two independent observers (SHR, GDU), who were unaware of the individual clinical histories at the time, suggested other causes for a difference in vertebral height (for example, anterior vertebral lesions or discitis). The lower limits of the normal ratio of vertebral heights $(0.80$ and 0.85$)$ were defined by measuring vertebral dimensions in the 54 consecutive patients ( 20 men, 34 women; median age 38 years, range 18-66) who had presented to the centre during the study with non-specific back pain. The radiograiphs for all these 54 patients were reported as normal. The median ratio of anterior to posterior vertebral height of the patients with non-specific back pain was 1.0 (range $0.86-1 \cdot 12$ ) for lumbar vertebrae and $0.92(0.80-1 \cdot 04)$ for thoracic vertebrae. Biconcave vertebral fractures were considered to be present when the ratio of the mid-vertebral height to posterior vertebral height was $<0 \cdot 80$. This figure was also derived from measurements in the patients with non-specific back pain, in whom the median values were $0.92(0.79-1.04)$ for thoracic vertebrae and 0.91 $(0.82-0.96)$ for lumbar vertebrae. These reference values correspond closely to those given by other workers ${ }^{84}$ and values in men and women were not significantly different (data not shown).

A scoring system was devised to measure the severity of spondylitis as shown by lateral radiographs of the spine. For the cervical, thoracic, and lumbar spine the anterior and posterior margins of each intervertebral space were scored 0 (no syndesmophytes), 1 (nonbridging syndesmophytes), or 2 (bridging syndesmophytes). An additional score of 1 was allotted for each posterior intervertebral facet joint in the cervical spine that was seen to be fused. Sacroiliac joints were scored on a scale of $0-4$ as previously described.$^{10}$ For statistical analysis an overall score for each region of the spine was obtained by adding the individual scores for C1/2-C6/7 (cervical, maximum score 30); T5/6-T11-12 (thoracic, maximum score 28), and T12/L1-L5/S1 (lumbar, maximum score 24). The appearance of the disc spaces T3/4 and T4/5 and the facet joints in the thoracolumbar. spine were not included as in many 
cases they were poorly visualised and could not be confidently assessed.

Agreement between the two observers for each region assessed (to within five arbitrary points) in $\mathbf{3 0}$ randomly selected patients was $62 \%$ for the cervical spine, $70 \%$ for the thoracic spine, and $96 \%$ for the lumbar spine. Agreement on the combined sacroiliac score (to within one grade) was $92 \%$.

Data were analysed by the Mann-Whitney U test.

\section{Results}

Ninety eight of the 111 patients with ankylosing spondylitis were men. The median age of the patients was 41 (range 19-76) and the median duration of the disease 17 years (range 1-48 years). Examination of spinal radiographs showed compression fractures associated with appreciable vertebral osteoporosis in 18 cases $(16 \%)$. In a further five patients biconcave fractures of the vertebral bodies were noted. Three patients with compression fractures were excluded from further analysis because other factors might have contributed to the fractures: postmenopausal state and primary hyperparathyroidism (one), age (one), and coexistent inflammatory bowel disease (one). In the remaining 15 patients other conditions that might have contributed to generalised osteoporosis or fractures (for example, trauma; endocrine disease such as thyrotoxicosis; hypogonadism and Cushing's syndrome; and alcohol abuse) were excluded by the clinical history, physical examination, and biochemical investigations.

The 15 patients with compression fractures were compared with 30 control patients (two for each patient), who were matched for age and sex and selected at random from the remainder of the study group. Matching for age resulted in a close match with regard to duration of disease (table I). Table I also gives data on the five patients who had "pure" biconcave vertebral fractures.

There was no significant difference in erythrocyte sedimentation rate, duration of disease, or density of the distal third of the radius between the groups (table I). In addition, height, weight, and $\mathrm{C}$ reactive protein concentration did not differ significantly (data not shown). The patients with compression fractures had a significantly higher score for the lumbar spine than the controls, which reflected increased formation of syndesmophytes, whereas those with biconcave fractures had increased scores in all three spinal regions. The patients with compression fractures or biconcave fractures had more spinal deformity, less spinal mobility, and more limited excursion of the chest wall than the controls despite the groups being

TABLE I-Clinical and laboratory details of patients with ankylosing spondylitis. Values are medians (ranges) ${ }^{\star}$

\begin{tabular}{lccc}
\hline & Controls & $\begin{array}{c}\text { Patients with } \\
\text { compression } \\
\text { fractures } \\
(\mathbf{n}=15)\end{array}$ & $\begin{array}{c}\text { Patients with } \\
\text { biconcave fractures } \\
(\mathbf{n}=5)\end{array}$ \\
\hline Age (years) & $38(25-62)$ & $41 \cdot 0(24-63)$ & $48(40-56)$ \\
Sex $(M / F)$ & $26 / 4$ & $13 / 2$ & $4 / 1$ \\
Duration of disease (years) & $16 \cdot 5(4-33)$ & $17 \cdot 0(3-38)$ & $18(10-29)$ \\
Erythrocyte sedimentation rate (mm in first hour) & $35(1-100)$ & $29(3-129)$ & $10(4-50)$ \\
Density of distal third of proximal radius $\left(\mathrm{g} / \mathrm{cm}^{2}\right)$ & $0 \cdot 77(0 \cdot 65-0 \cdot 88)$ & $0 \cdot 75(0 \cdot 66-0 \cdot 88)$ & $0 \cdot 78(0 \cdot 69-0 \cdot 83)$ \\
Distance from wall to tragus $(\mathrm{cm})$ & $12 \cdot 7(10-34)$ & $24 \cdot 5 \neq(11-38)$ & $24 \dagger(16-39)$ \\
Result of spondylometry (degrees of flexion) & $46 \cdot 5(7-100)$ & $20 \dagger(7-60)$ & $27(16-65)$ \\
Chest expansion $(\mathrm{cm})$ & $3(1-10)$ & $2 \dagger(1-6)$ & $1(0 \cdot 5-3)$ \\
Vertebral score: & $2(0-25)$ & $8(0-20)$ & $21 \dagger(5-25)$ \\
$\quad$ Cervical & $0 \cdot 5(0-28)$ & $6 \cdot 0(0-25)$ & $21 \dagger(0-28)$ \\
$\quad$ Thoracic & $0(0-20)$ & $2 \dagger(0-20)$ & $7 \dagger(0-16)$ \\
$\quad$ Lumbar & $7(3-8)$ & $8(5-8)$ & $7(6-8)$ \\
Combined score for sacroiliac joint & & & \\
& & &
\end{tabular}

*Reference ranges: erythrocyte sedimentation rate, $<30 \mathrm{~mm}$ in first hour; density of distal third of proximal radius (patient aged 20-50), woman 0.47-0.77 cm, man 0.6-0.81 cm; chest expansion, $\geqslant 5 \mathrm{~cm}$; distance from wall to tragus, $<12.5 \mathrm{~cm}$; result of spondylometry, $>70^{\circ}$ of flexion."

$\mathrm{tp}<0.05$

$\neq \mathrm{p}<0.005\}$ from the control group.

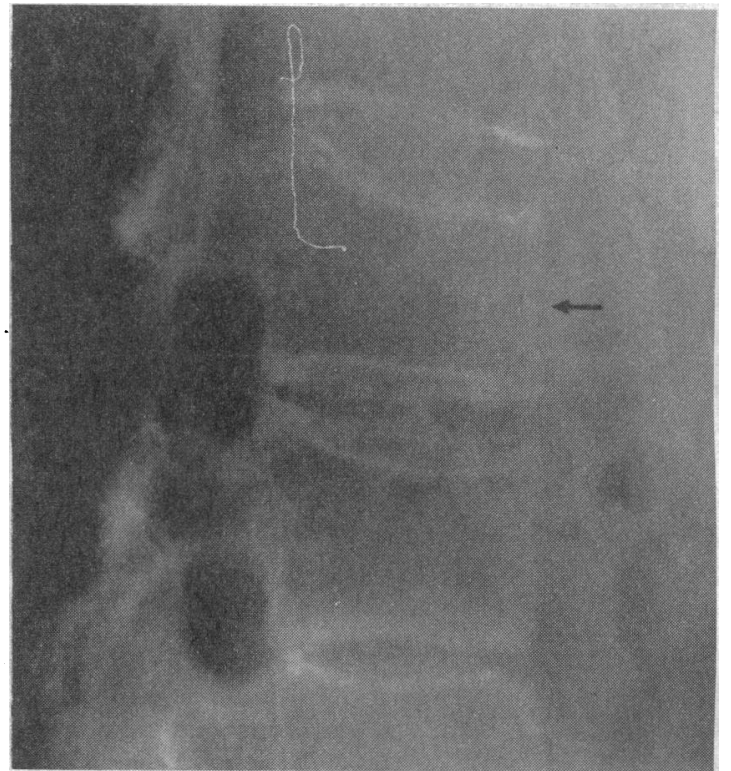

FIG 1-Radiograph of lumbar spine of 44 year old man with 14 year history of ankylosing spondylitis, showing considerable osteopenia and compression fractures of $L 2$ (arrowed) and, to lesser extent, L3. Note "squaring" of anterior border of L3 and L4 typical of ankylosing spondylitis

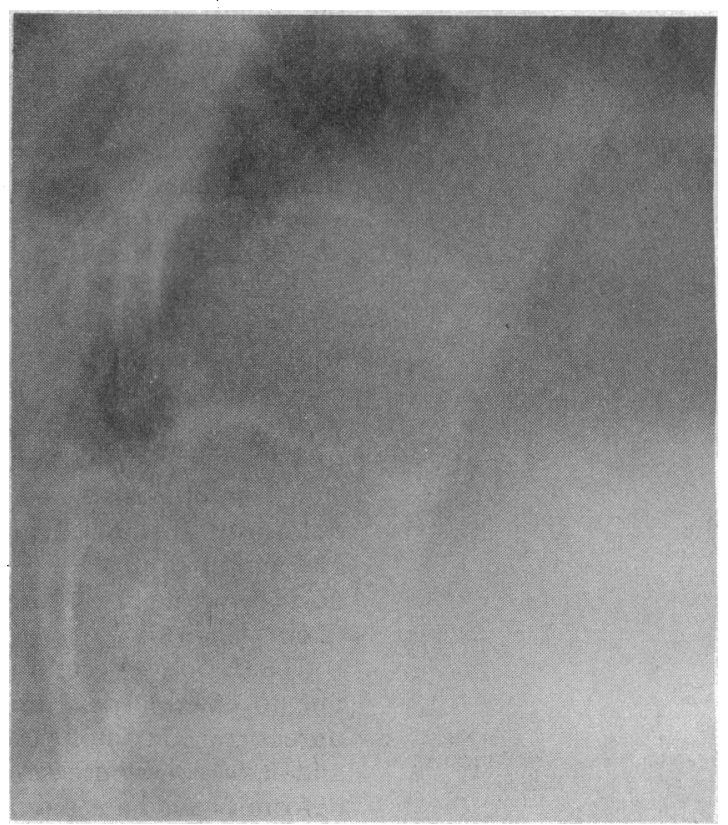

FIG 2-Radiograph of lower thoracic spine of 44 year old premenopausal woman with 10 year history of ankylosing spondylitis, showing ballooning of intervertebral discs, considerable formation of syndesmophytes and "squaring" of anterior vertebral bodies; syndesmophyte were evident throughout her spine

closely matched for sex and age and having a similar duration of disease.

Figure 1 shows a radiograph of a typical compression fracture, with a wedge deformity affecting vertebrae $\mathrm{L} 2$ and, to a lesser extent, L3 in association with severe spinal osteoporosis. No bridging syndesmophytes are seen near the lesion, and this was the case in 14 of the patients with compression fractures. In contrast, four of the five patients with biconcave fractures had considerable syndesmophyte formation in the affected vertebrae (fig 2).

The compression fractures were distributed throughout the lumbar and thoracic spine, T6 and L2 being most commonly affected (table II). Eight patients had one fracture, four had two, two had three, and one had five. Two patients with multiple compression fractures also had evidence of biconcave fractures in other vertebrae. When biconcave fractures were 
TABLE II - Site and number of vertebral compression fractures in patients with ankylosing spondylitis

$\begin{array}{lcccccccccccccc}\text { Vertebra: } & \text { T4 } & \text { T5 } & \text { T6 } & \text { T7 } & \text { T8 } & \text { T9 } & \text { T10 } & \text { T11 } & \text { T12 } & \text { L1 } & \text { L2 } & \text { L3 } & \text { L4 } & \text { L5 } \\ \text { No: } & 1 & 2 & 5 & 1 & 3 & 3 & & 1 & 3 & 2 & 5 & 1 & & \end{array}$

present in isolation they were confined to the lower thoracic and lumbar vertebrae T9-L5, with four of the five patients having two affected vertebrae and the remaining patient one affected vertebra.

\section{Discussion}

Vertebral osteoporosis is a well recognised radiological feature of advanced ankylosing spondylitis. ${ }^{1-3}$ Despite this, fractures related to osteoporosis are considered rare,${ }^{56}$ possibly because of the assumption that the formation of syndesmophytes protects the rigid spondylitic spine against fractures. Our study indicates that this is not so. Unlike in previous studies, in which vertebral fracture was documented as a complication of spinal trauma in patients with ankylosing spondylitis,${ }^{46}$ none of our patients had a history of back injury that could have accounted for the fracture. We suggest that most of the fractures were essentially spontaneous and the result of the osteoporosis, which was obvious even by the insensitive technique of radiography.

Probably many of the fractures noted in this study had been present for some time before they were recognised but the pain associated with them had been overlooked or attributed to exacerbations of the spondylitic process. For example, the patient who prompted this study was admitted because of a suspected exacerbation of spondylitis and was found to have multiple vertebral fractures only when lateral radiographs of the spine were obtained. Seven of the patients with compression fractures had also required admission to hospital during the preceding five years because of acute back pain, which had similarly been attributed to exacerbations of the spondylitic process. Though it is tempting to suggest that these and other episodes of back pain may have been due to fractures, lateral radiographs of the spine had in many cases not been obtained before this study.

In addition to their potential role in causing back pain, the compression fractures probably also contributed to patients' spinal deformity. Although all patients with ankylosing spondylitis are prone to develop spinal deformity and loss of movement, the patients with fractures had more spinal deformity and less mobility of the spine and chest than those without despite a similar duration of disease and similar age, sex, and laboratory variables of activity of the disease.

Indeed, the only significant difference between the patients with compression fractures and controls was the slightly greater number of syndesmophytes in the lumbar spine in the patients. Interestingly, the patients with biconcave fractures tended to have more extensive formation of syndesmophytes throughout the spine than the controls and the patients with compression fractures. Anteriorly placed syndesmophytes may protect against crush fractures by buttressing the anterior vertebral body. In keeping with this hypothesis, anterior bridging syndesmophytes were rarely observed near vertebrae that were affected by compression fractures.

The prevalence of fracture in this study is far greater than that previously reported in Europe or North America, ${ }^{56} 12-14$ although a high prevalence has been noted in Turkey. ${ }^{11}$ Presumably, no documented association between ankylosing spondylitis and osteoporotic fracture exists in standard texts ${ }^{12-14}$ because of difficulties in clinical diagnosis and the fact that many investigators have been more concerned with analysing other radiological features of the disease. ${ }^{12}$
Interestingly, the patients with compression fractures had normal appendicular bone density (judged by single photon absorptiometry at the distal third of the dominant radius) but considerably reduced spinal bone density (shown by the vertebral osteoporosis and compression fractures). The spinal osteoporosis may have been a predominantly local phenomenon related to immobility or release of cytokines by inflammatory cells in the paraspinal tissues. ${ }^{15}$ Alternatively, more generalised loss of bone may have occurred but in trabecular rather than cortical bone. Regrettably, we did not have access to more sophisticated techniques for measuring the mineral content of bones, which would have allowed us to investigate this further. ${ }^{16}$

Although bone density has been measured in patients with ankylosing spondylitis, the high incidence of extraskeletal calcification in paraspinal tissues makes interpretation difficult. Thus, Reid et al found that total body calcium (measured by neutron activation analysis) in patients with ankylosing spondylitis was initially low and generally fell over 18 months whereas the density of lumbar bone was initially normal or high and tended to increase during follow up. ${ }^{17}$ More recently, Will et al found normal bone density at the wrist and appreciably reduced density in femoral and spinal bones in patients with spondylitis who were studied at an early stage in the disease process, before syndesmophytes had formed.$^{18}$ Our findings concur with those cited above and confirm that, whatever the underlying cause, the distribution of the osteoporosis in ankylosing spondylitis is predominantly axial.

In ankylosing spondylitis most attention has focused on the pathogenic role of the formation of new bone and ligamentous calcification. ${ }^{12512-14}$ Our study and others, however, show that bone loss is equally important and can lead to osteoporotic fracture in a high proportion of cases. ${ }^{17}{ }^{18}$ Such fractures are easily overlooked clinically but may be recognised in lateral radiographs of the thoracolumbar spine. Osteoporotic fracture should be considered in any patient with ankylosing spondylitis who presents with an acute and otherwise unexplained episode of back pain even in the absence of trauma.

1 Resnick D, Niwayama G. Ankylosing spondylitis. In: Resnick D, Niwayama G, eds. Diagnosis of bone and joint disorders. Vol 2. Philadelphia: W B G, eds. Diagnosis of

2 Spencer DG, Park WM, Dick HM, Papazoglou SN, Buchanan WW Radiological manifestations in 200 patients with ankylosing spondylitis correlation with clinical features and HLA B27. F R heumatol 1979;6:305-15

3 Polley HF. The diagnosis and treatment of rheumatoid spondylitis. Med Clin North Am 1955;39:509-29.

4 Hunter T, Dubo HIC. Spinal fractures complicating ankylosing spondylitis: long term study. Arthritis Rheum 1983;26:751-9.

5 Wilkinson M, Bywaters EGL. Clinical features and course of ankylosing spondylitis. Ann Rheum Dis 1958;17:209-28.

6 Hanson CA, Shagrim JW, Duncan H. Vertebral osteoporosis in ankylosin spondylitis. Clin Orthop 1971:74:59-64.

7 Sturrock RD, Woitulewski JA, Hart FD. Spondylometry in a normal population and in patients with ankylosing spondylitis. Rheumatology and population and in patients with
Rehabilitation 1973;12:135-42.

8 Hurxthal LM. Measurement of anterior vertebral compressions and biconcave vertebrae. Radiology 1968;103:635-44.

9 Barnett E, Nordin BEC. The radiological diagnosis of osteoporosis: a new approach. Clin Radiol 1960;11:166-74.

10 Macrae IF, Haslock DI, Wright V. Grading of films for sacroilitis in population studies. Ann Rheum Dis 1971;30:58-66.

11 Dilsen N. Romatizmal hastaliklarda vertebral osteoporoz hakkinda. Türk Tip Cemiyeti Mecumuasi 1964;30:362-70.

12 Hart FD. Clinical features and complications. In: Moll JMH, ed. Ankylosin spondylitis. Edinburgh: Churchill Livingstone, 1980:52-68.

13 Bluestone R. Ankylosing spondylitis. In: McCarty DJ, ed. Arthritis and allied conditions. 10th ed. Philadelphia: Lea and Febiger, 1985:819-40.

14 Moll JHM. Ankylosing spondylitis. In: Scott JT, ed. Copeman's textbook of the rheumatic diseases. 5th ed. Edinburgh: Churchill Livingstone, 1978:511-36.

15 Raisz LG. Local and systemic factors in the pathogenesis of osteoporosis. NEngl f Med 1988:318:818-28.

16 Murby B, Fogelman I. Bone mineral measurements in clinical practice. Mrf Hosp Med 1987;37:453-8.

17 Reid DM, Nicoll JJ, Kennedy NSJ, Smith MA, Tothill P, Nuki G. Bone mas in ankylosing spondylitis. I Rheumatol 1986;13:932-5.

18 Will R, Palmer R, Ring F, Calin A. Ankylosing spondylitis is associated with marked osteopenia of the lumbar spine and femoral neck in patients with mobile spines and hips [Abstract 37]. Br J Rheumatol 1989;28(Suppl 1):19.

(Accepted 15 December 1989) 